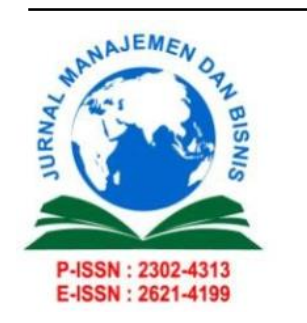

\author{
Jurnal Manajemen dan Bisnis \\ Vol. 9, No. 2, December 2020, pp. 119-132 \\ Sekolah Tinggi Ilmu Ekonomi Indragiri (STIE-1) Rengat \\ https://journal.stieindragiri.ac.id/index.php/jmbi/issue/view/15
}

\title{
CONTROLLING THE CHANGING OF MANAGEMENT ACCOUNTING PRACTICES IN THE ENTERPRISE RESOURCES PLANNING ENVIRONMENT
}

\author{
Muhammad Nawawi ${ }^{1}$, Roza Mulyadi ${ }^{2}$, Dabella Yunia ${ }^{3}$ \\ 1) 2) 3) Universitas Sultan Ageng Tirtayasa \\ ${ }^{1)}$ muhammadnawawi.ac.id \\ Submited: 2020.10.07 Reviewed: 2020.12.07 Accepted: 2020.12.31 \\ https://doi.org/10.34006/jmbi.v9i2.196
}

\begin{abstract}
The aims of this research is to give empirical evidence of changes in management accounting practices (MA) by examining the effects of changes in data quality, information quality and management accounting tasks on the efficiency and effectiveness of accounting, and indirectly on change in management accounting after the adoption of an enterprise resource planning (ERP) systems. Empirical analysis of the study used primary data from a survey of 29 manufacturing companies with 102 CFO respondents, accounting managers and business controllers, with a response rate of $28.43 \%$, providing significant support for the proposed model. Structural equation modeling (SEM) approach with testing tools using partial least square (PLS) is used in this research. The linear thing with the results of previous research is the same, it was found that the erp implementation time is the determinant of significant MA changes, while the difference from previous researchers is in the end user, where the company that has adopted the ERP system has just felt a greater MA change when compared to users early on. The results showed that the implementation of global ERP and the use of business intelligence tools (BI) were significantly related to changes in MA practices.
\end{abstract}

Keywords: Management accounting; ERP; business intelligence.

\section{INTRODUCTION}

Over the past 20 years, the enterprise resource planning system (ERP) has become well known to medium and large companies around the world. This ERP includes "integrated organizational information system that enables an organization to manage and coordinate all its information, resources, and functions from a shared database. Therefore, ERP can be used to integrate all the company's information in one centralized database, their information is taken from a variety of different organizational functions by helping to provide visible objects for the organization" (Dechow and Mouritsen, 2005; Kallunki et al, 2011).

although the use of ERP has been widespread but knowledge of its effects on accounting management (AM) is still rare (Sutton, 2006; Vakalfotis et al, 2011). But it is necessary "to learn the well-functioning relationship between the use of ERP and AM, because ERP systems are supposed to provide easy and fast access to operational data, and the role of AM is to pass that data on to relevant and useful management" (Cooper and Kaplan, 1998). Arnold and Sutton (1998). Likewise Hunton (2002) and Sutton (2006) "also argued that in general practice for 
accounting logic to be reviewed and could change why organisations make large-scale changes to information systems." Next, the researchers (Hunton, 2002; Sutton, 2006) "stated that the ERP system will affect all areas of accounting." Findings from an existing preliminary study on "the impact of ERP on am show, however, that ERP systems have only a limited impact on AM practices" (Granlund and Malmi, 2002; Scapens and Jazayeri, 2003). Booth et al (2000) argue that "one of the main reasons is that ERP systems are effective in transaction processing, but less effective in reporting and supporting decision making." However, "organizations continue to make substantial business investments into ERP systems, so it is increasingly important to understand the extent to which ERP systems affect AM practices" (Sutton, 2006; Rom and Rohde, 2006; Granlund, 2011).

The purpose of this research is to test the impact of erp system usage on AM changes by examining the effects of changes in data quality, information quality, role and task of management accountants on the efficiency and effectiveness of accounting. in addition, there are also changes measured as changes in AM techniques. The hypothesis of this research was taken from online/electronic survey questionnaire data on large and medium enterprises in Banten.

Similarly, in this study, in this study how long the implementation of ERP in a company will have an effect on determining significant changes in the company, but from this research also found that companies that use ERP systems recently feel a greater AM change than the first company to implement this. Furthermore, the results showed that the implementation of global ERP and the use of business intelligence (IB) tools were significantly related to changes in AM practices. This research is a replication of research conducted gullkvist (2013) on large and medium enterprises in Finland. The author applies the same model with the objects of large and medium enterprises in Indonesia, especially industrial estates in Banten Province with different industrial culture and regulations than previous research.

According to Kondalkar (2009) "states that the effectiveness of the organization depends largely on the effectiveness of its sub-systems, including accounting functions." And Based on previous empirical research, that the relationship between information technology and accounting management can be researched by quantitative or qualitative research approach. Vakalfotis et al. (2011) "provides an overview of previous studies of ERP systems, which argue that most previous empirical studies tended to focus on the picture of changes in AM practice and the role of management accountants resulting from erp implementation rather than analyzing and understanding such changes." Granlund and Malmi (2002) "developed a theoretical model for the impact of ERP systems on AM and accountants. They propose the direct and indirect effects of the ERP system on management accountants and AM." The immediate effect will occur when erp system implementation directly changes reporting practices. Indirect effects are AM changes resulting from changes in management practices or business processes, initiated by ERP implementations. Rom (2008) "presents a theoretical model to describe the relationship between integrated information systems and AM." The Roman model (2008) "divides AM into four parts i) tasks, ii) techniques, iii) AM organizations, and iv) user behavior, usage, and perception."

In previous research, it was mentioned that in order to improve effectiveness and efficiency in an organization needs to be implemented ERP system (Hevner et al., 2004). The effectiveness of the function shows the extent to which predetermined goals are met, "while efficiency refers to the economical way in which goal-oriented operations are carried out, usually measured as an input/output ratio" (Kondalkar, 2009). Efficiency and effectiveness have also been shown in previous studies as a measure of system success (Smithson and Hirschheim, 
1998). However, the extent to which these goals will be achieved depends on several factors such as information system capability (SI) and organizational characteristics system, human resources, and methodology of development and implementation (Silver et al., 1995 in Gulkvist, 2013). DeLone and McLean (1992) "consider the success of SI as a multi-dimensional construct that includes measures of quality (system and information quality), attitude results (use and satisfaction), and results related to performance (individual and organizational effects)."

DeLone and McLean describe that (1992) "have been widely accepted as SI success models" (Tsai et al, 2011), but have also been criticized for their weak theory of applying the use of SI as one of the key variables of the model. Bradley et al (2006) argue that "not the use of the information system itself but the impact of si use on organizations is important and represents a measure of success." Therefore, this study used the impact of AM (measured as efficiency and effectiveness) as a measure of ERP success to represent the results of ERP use on AM. Scapens and Jazayeri (2003), "in identifying the drivers of AM change through longitudinal case studies, emphasized four software characteristics such as SAP in question integration, standardization, routinization and centralization, but also noted that the system seems to change the work of management accountants." Therefore, given that ERP system implementation is often accompanied by major changes in the way it works (Grabski and Leech, 2007; Kallunki et al, 2011) to improve efficiency in the work of the organization (Bernroider, 2008), it is recommended that aspects related to the task (which are considered related to individual users) should be included in the research model as independent variables rather than as a result. In short, the study considers efficiency and effectiveness as intermediate variables between independent variables (data quality, information quality, tasks) and dependent variables (changes in AM practice).

Previous research has considered the time spent since "ERP implementation, it is important when studying the effects of ERP implementation on the accounting process" (Gulkvist, 2013). It says that longer periods of use will help organizations develop their expertise with the system more effectively and generate business benefits. Granlund and Malmi (2002) argued that "some features, such as analytical tools (business intelligence tools), were not included in the initial ERP implementation, which could slow the adoption of new AM techniques."Nicolaou and Bhattacharya (2006) "stated that due to problems and decreased performance after implementation, positive financial performance should not be expected until after a period of at least two years has passed since adoption." Furthermore, the research model will be described in figure 1 . below.

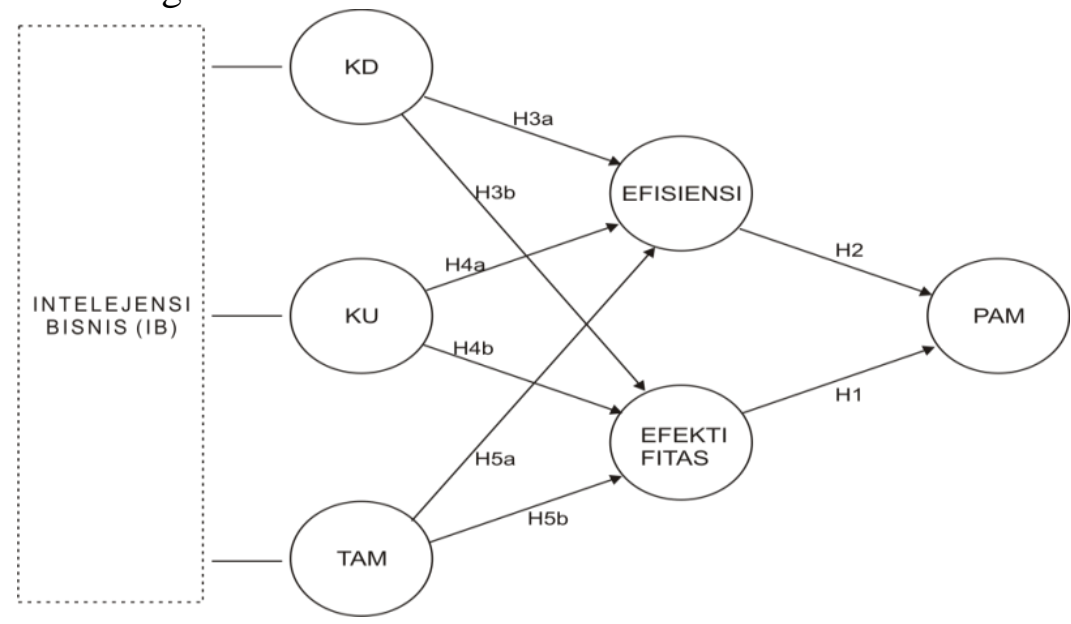

Figure 1. Research Model 
Moreover, although Scapens and Jazayeri (2003) "found in their research that sap software implementation in the European division of large U.S." This research has the ultimate goal, to find out why multinational companies do not lead to the adoption of more advanced AM techniques. This is because previous research has argued that technological change requires fundamental changes in performance measures and methods (Drury and Tayles, 1995). Rom and Rohde (2006) state that "however, despite the lack of adoption of new AM techniques, ERP systems will increase users' knowledge of these new techniques, which are seen as a starting point for further development." then from this research is expected to obtain the ultimate goal of erp system implementation is the existence of fundamental improvements or changes of AM techniques, achieved through successful ERP implementation. The indications are the increase in efficiency and effectiveness of AM practice. It is also mentioned that the characteristics of am technology and tasks will help in achieving efficient and effective AM practices (Gulkvist, 2013). Positive relationships are hypothesized there are between all the variables in the model. Variables are modified to the current context based on previous studies. The research model, as illustrated in Figure 1, is controlled for corporate and technological characteristics.

This research model uses a direct path between constructs. DeLone and McLean (2003) "suggest in their model that the relationship between SI use and the net benefits (effects) of the system may be complicated, since the benefits may arise from using the system, but positive or negative feedback and feedforward can affect and further strengthen used." While acknowledging that a two-way relationship in this study is highly likely between efficiency/effectiveness and changes in AM practice and also between technological characteristics, AM tasks and efficiency/effectiveness, previous studies seem to consider and support a one-way direction. (Granlund and Malmi, 2002) "argue that it is more likely that ERP systems will have an effect on AM practices than vice versa since ERP system configuration is difficult to change after implementation." Therefore, the study adopted a one-way linear relationship, but it was noted as a limitation of the research. The proposed research and relationship models will then be discussed in more detail.

It has been stated that IT resources create economic value by increasing operational efficiency and creating competitive advantages (Melville et al., 2004; Rai et al., 2006). Although the organizational impact of IT/SI has been measured in a number of ways in previous studies (Gorla et al., 2010), research in AM considers efficiency and effectiveness as two key indicators in assessing and measuring organizational performance related to accounting practices and information technology. As stated, one of the main areas and objectives of ERP implementation is to achieve increased efficiency and effectiveness of organization and accounting functions. In this study, efficiency and effectiveness were used as mediators to investigate changes in AM techniques. Laitinen (2002) "presents two dimensions, cost and quality, in the measurement of activity performance." These dimensions have been modified and used as dimensions to measure MA efficiency after ERP adoption. Thus, the items used relate to the am departmental cost and the quality of AM's work (Gullkvist, 2013).

Nicolaou (2000) "defines the effectiveness of accounting information systems based on the perception of decision-makers whether output information is available to them through transaction processing, management reporting, and budgeting systems meeting their requirements for organizational control." He also stressed the importance of continuous monitoring as an indicator of effective internal accounting and control systems. Nicolaou's research (2003) "showed that effectiveness can be evaluated using indicators such as i) Reports (e.g. Daily or weekly reports) are often given, systematically and regularly; ii) Accounting 
information systems provide useful information for monitoring decisions and ongoing actions. These indicators were modified and used as instruments to measure effectiveness in this study."

Regarding this research model, it is proposed that increased efficiency and effectiveness in accounting practices will facilitate (in the sense of providing time and resources for) the improvement and development of AM practices and thus trigger a change of existing practices. Thus, it is proposed that improved accounting efficiency and effectiveness will positively affect changes in AM practice, here measured as changes in AM techniques. This is stated in the following two hypotheses:

H1: There is a positive relationship between efficiency and change in AM practice

H2: There is a positive relationship between effectiveness and change in AM practice

Data quality is defined by Park and Kusiak (2005) "as a measure of the agreement between the view of data presented by ERP and the same data in the real world. Data quality has been considered important for the quality of information because poor data quality results in poor information quality." Poor data quality, and therefore poor information quality, have an adverse effect on organizations at an operational, tactical and strategic level (Redman, 1998). Among others, Sangster et al, (2009) "reported that ERP systems that are successfully implemented have automatic data collection and information quality improvement, which is in line with previous research showing that ERP systems are effective in information processing."

Ballou and Pazer (1985) in Gulkvist (2013) "identified four dimensions of data quality: data accuracy, data timeliness, completeness and consistency. Data accuracy means that the recorded data corresponds to the actual value, the completeness of the data implies that all data for a particular variable is recorded and the consistency of the data that the representation of the value of the data is the same in all cases." This dimension (with the exception of data timeliness) is included as a measurement item in this study. It is proposed that positive changes in data quality will positively affect the efficiency and effectiveness of accounting functions and practices.

H3a: There is a positive relationship between changes in quality and data efficiency

H3b: There is a positive relationship between changes in quality and data effectiveness

In addition, if end-user needs are not met by the information system (IS), it will result in greater costs for the organization's operations and maintenance costs (Swanson, 1997). Therefore, it is said that the high quality of information (i.e. accurate, complete, and relevant information) leads to better cost control and improved organizational efficiency (Improved profit margins, improved decision-making efficiency) (Gorla et al., 2010). In addition, inaccurate or incomplete information can lead to job dissatisfaction and the quality of decision making can be negatively affected by irrelevant information. Spathis (2006) "reports that information management in ERP systems ranks among the highest accounting benefits obtained from the implementation of ERP systems." The following benefits were stated by respondents: increased flexibility in information creation, improved application integration, improved report quality, faster report publishing, improved decisions based on timely and reliable accounting information, and faster year-end accounting procedures. Their study further found, in contrast to some other previous studies, a significant relationship between ERP systems, reporting and decision making. In addition, Granlund and Malmi (2002) "argue for greater report accuracy and information improvement as a result of ERP implementation in their exploratory studies." Scapens and Jazayeri (2003) "emphasized that the availability of information from SAP systems is increasing and that information is more up to date." Drawing on the previous study above it is proposed here that the ERP system will affect the quality of information, which in turn will have 
an impact on the efficiency and effectiveness of accounting functions. This is stated in the following hypothesis:

H4a: There is a positive relationship between changes in information quality and efficiency

H4b: There is a positive relationship between changes in the quality and effectiveness of the information

Scapens and Jazayeri (2003) "noted the following four changes in the work of management accountants: the elimination of routine work that leads to a reduction in the size of accounting functions; increased accounting knowledge requirements for line managers; more forward-looking information provided by ERP, allowing them to produce better forecasts; and broader knowledge of the business that management accountants need, as they are much more involved in the management team." Similarly, Sangster et al. (2009) "found that ERP implementation resulted in a change in the task of the management accountant. It is also concluded that when ERP implementation is successful, management accountants have more time for other activities and their roles become more enriching." Drawing on this study, the proposal made here is that changes in the duties and roles of management accountants will positively affect the efficiency and effectiveness of management accounting in the company, which will provide free time for development and to apply changes to AM practices. It is stated as follows:

H5a: There is a positive relationship between duty and efficiency

H5b: There is a positive relationship between duty and effectiveness

\section{RESEARCH METHOD}

\section{Data and Surveys}

Survey data collected through electronic-based forms are used to test hypotheses. Companies in Banten are small in size will not have integrated information systems with systematic AM and analysis-oriented components. Therefore, the target is given to large and medium-sized companies. Based on the law no. 20 of 2008 mentioned that medium enterprises as a company that has 50 to 200 employees and has a turnover of between 2.5 billion to 500 billion rupiah, assets between 1 billion to 15 billion rupiah. Companies those are considered to be medium and large companies are measured based on criteria. Random sampling is used because there is no data recording specifically available whether the company has adopted an ERP system. There are 2 questions that are prepared if a company does not respond to the implementation of ERP system, the question is related to the implementation time and scope of ERP. The data base of this study includes information about the company's senior executives and management in Banten, email addresses of CFO, Financial Managers, Business Controllers, and equivalent job positions collected. the selection of this group of respondents because they are expected to have knowledge of the effect of erp systems on AM and possible changes in AM practices. The questionnaires consist of 120 , were sent by email to respondents, either personal or corporate e-mails.

Following the design methods of Dillman Tailored (2000), "in the design and administration of questionnaires, the survey instruments were trialed by a group of academics and practitioners and distributed after minor changes via e-mail with a cover letter explaining the purpose of research and practice responses." At any time, independent and dependent variables are measured using several existing indicators from previous studies.

Respondents were given 15 days to fill out an online questionnaire with two reminder messages. It's obtained a response rate of 36 percents; this was obtained from 37 responses that 
have been collected to the end. Some email addresses are wrong so cause this to be restored by the system, this is the cause of the response rate to be low. In addition, there are some respondents who do not respond according to the target achieved; this is because there are companies that apply spam filters in their company emails, so they cannot receive the email. And from the data obtained, obtained, from 37 responses received, 5 could not be used because the company did not adopt an ERP system, and 3 responses were incomplete. So from the data only 29 responses were acceptable or equivalent to 28.43 percent.

Table 1. Distribution of Research Questionnaires

\begin{tabular}{lccc}
\multicolumn{1}{c}{ Sending } & Number & Return & Response rate \\
& & & \\
\hline Questionnaires & 102 & 37 & $36,27 \%$ \\
$\begin{array}{l}\text { Questionnaire } \\
\text { Used }\end{array}$ & & 29 & $28,43 \%$ \\
\hline
\end{tabular}

Source: Processed primary data (2019)

The companies that answered represented the following different industries: manufacturing (66\%), trade (28\%) and services $(7 \%)$ Respondents were: CFO (21\%), business controller (72\%) and chief financial accountant $(7 \%)$. based on the test t conducted, this result was obtained that showed insignificant differences between respondents from the CFO group and controllers / accountants, although it was seen that they operated at different hierarchical levels. One explanation for this is that all respondents, despite having a variety of titles, operate at a managerial level, something that can be expected due to the choice of databases used to source email addresses. Erp system implementation time used by the company is at least 3 years.

\section{Accounting Management Techniques and Business Intelligence Tools}

based on this research obtained response that a company performs several stages of application, namely, new, new AM techniques for the organization and after ERP implementation. The instruments used were adopted from previous research (Waldron, 2007; Rom 2008). Based on table 2 it can be seen that the most common AM techniques applied after ERP implementation are the main performance indicators, but other techniques also appear despite their low levels. Based on further analysis, it was obtained that 3 respondents have adopted activity-based costs, 1 respondent has adopted a balance scorecard technique, 2 respondents use comparative analysis, 2 respondents have adopted a customer satisfaction survey, 11 respondents use key performance indicators, 6 respondents use cost targets and 4 respondents adopt lifecycle costs. 
Table 2. Company Adopted New Techniques of Accounting Management

\begin{tabular}{lcc}
\multicolumn{1}{c}{ Respondents } & Respondents user & Percentage \\
\hline Activity-based costing & 3 & $10,34 \%$ \\
Balance scorecard & 1 & $3,45 \%$ \\
Comparative analysis & 2 & $6,90 \%$ \\
Customer satisfaction surveys & 2 & $6,90 \%$ \\
Key performance indicator & 11 & $37,93 \%$ \\
Target costing & 6 & $20,69 \%$ \\
Life cycle costing & 4 & $13,79 \%$ \\
\multicolumn{1}{c}{ Total } & 29 & $100 \%$ \\
\hline
\end{tabular}

Source: Gulkvist (2013), Processed primary data (2019)

\section{RESULTS AND DISCUSSION}

Partial Square Line analysis (PLS) modeling techniques, using Smart PLS version 3 were used to test this research model(Ringle et al., 2005). PLS estimates that structural models use procedures similar to OLS regression, but do not aim for model optimization, nor do they report the suitability of the entire model (see Chin, 1998). All constructions are modeled using reflective indicators. The analysis of this research follows a two-stage approach (Barclay et al., 1995) in which it first assesses structural model testing, then assesses the reliability and validity of the model..

\section{Model Measurement and Data Quality}

Based on the SEM-PLS testing procedure, the evaluation of the validity of construct convergents using indicators in the form of loading factor and average variance extracted (AVE) (Kock, 2015). Consistency of factor loading/cross loading various operationalization tested using factor loading/cross loading value against constructs that are statistic significant can be assessed with convergent validity. The factor loading value used in this study is above 0.7 (Ghozali, 2011), and each construct must have an AVE value above 0.5 (Ghozali, 2011). Table 3 below shows the test results with SmartPLS. There are 18 data that must be eliminated because they have values below 0.7. As well as ave values above 0.5 can be seen in table 4 .

Table 3. Measurement Model

\begin{tabular}{ccccccc} 
& KD & KU & TAM & EFIS & EFEK & PAM \\
\hline KD1 & 0.779 & 0.838 & 0.700 & $0.624 *$ & 0.872 & 0.808 \\
KD2 & 0.797 & 0.936 & 0.748 & 0.778 & 0.770 & 0.801 \\
KD3 & 0.783 & 0.871 & 0.734 & 0.854 & $0.649 *$ & 0.792 \\
KU1 & 0.815 & 0.861 & $0.674 *$ & 0.847 & 0.728 & 0.752 \\
KU2 & 0.805 & 1.041 & 0.794 & $0.671 *$ & 0.787 & 0.770 \\
KU3 & 0.790 & 0.908 & 0.726 & 0.716 & 0.778 & 0.820 \\
KU4 & 0.792 & 0.832 & 0.803 & $0.675^{*}$ & 0.800 & 0.724 \\
TAM1 & $0.522^{*}$ & 0.730 & $0.588^{*}$ & 0.722 & 0.808 & 0.917 \\
TAM2 & 0.724 & 0.787 & 0.745 & $0.604 *$ & 0.801 & 1.017 \\
TAM3 & $0.624 *$ & 0.778 & 0.707 & 0.790 & 0.792 & 0.934
\end{tabular}




\begin{tabular}{cccccccc}
\hline TAM4 & 0.778 & 0.800 & 0.744 & 0.850 & 0.752 & 0.847 \\
EFI1 & 0.854 & 0.808 & 0.872 & 0.730 & 0.770 & $0.671^{*}$ \\
EFI2 & 0.847 & 0.801 & 0.770 & 0.748 & 0.820 & 0.716 \\
EFI3 & $0.671^{*}$ & 0.792 & $0.649^{*}$ & 0.734 & 0.724 & $0.675^{*}$ \\
EFEK1 & 0.716 & 0.752 & 0.728 & $0.674^{*}$ & 0.917 & 0.722 \\
EFEK2 & $0.675^{*}$ & 0.770 & $0.656^{*}$ & 0.794 & 1.017 & 0.800 \\
EFEK3 & 0.722 & 0.820 & 0.704 & 0.815 & 0.847 & 0.808 \\
PAM1 & $0.604^{*}$ & 0.724 & $0.508^{*}$ & 0.805 & $0.671^{*}$ & 0.801 \\
PAM2 & 0.790 & 0.917 & 0.852 & 0.790 & 0.716 & 0.792 \\
\hline
\end{tabular}

The assessment of discriminant validity in this study was conducted by comparing ave square root value with correlation value between constructs. Table 4 below shows that the discrete validity criteria contain ave square root values greater than the correlation coefficients between constructions (Ghozali, 2011; Kock, 2015).

Table 4 below also shows how criteria reliability has been met with the composite reliability value of each construct or latent variable has above 0.7 which indicates that the internal consistency of the inter-variables has good reliability. In short, "it is concluded that all scales behave reliably, demonstrate satisfactory convergent and discriminatory validity and demonstrate adequate psychometric properties" (Kock, 2015).

Table 4. Quality Data Measurement

\begin{tabular}{lcccc} 
Constructs & R-square & $\begin{array}{c}\text { Composite } \\
\text { Reliability }\end{array}$ & AVE & $\sqrt{ }$ AVE \\
\hline KD & 0.000 & 0.712 & 0,670 & 0,819 \\
KU & 0.000 & 0.794 & 0,669 & 0,818 \\
TAM & 0.000 & 0.707 & 0,688 & 0,829 \\
EFIS & 0.959 & 0.709 & 0,619 & 0,787 \\
EFEK & 0.998 & 0.711 & 0,641 & 0,801 \\
PAM & 0.857 & 0.701 & 0,551 & 0,742 \\
\hline
\end{tabular}

Source: Processed smartPLS output (2019)

\section{Structural Models and Hypothesis Testing}

The number of t-statistical values and the coefficient of the construction path can be used to test the proposed hypothesis, where the threshold for rejecting and accepting the proposed hypothesis is \pm 1.96 . If the value $t$ is in the range of values -1.96 to 1.96 and the coefficient value of the path is below 0.70 , then this hypothesis will be rejected, this is called the zero hypothesis (H0). for clearer information, then the results of the statistical estimate $t$ can be seen in figure 2 of the construction test results and the weight table results are in table 5. 


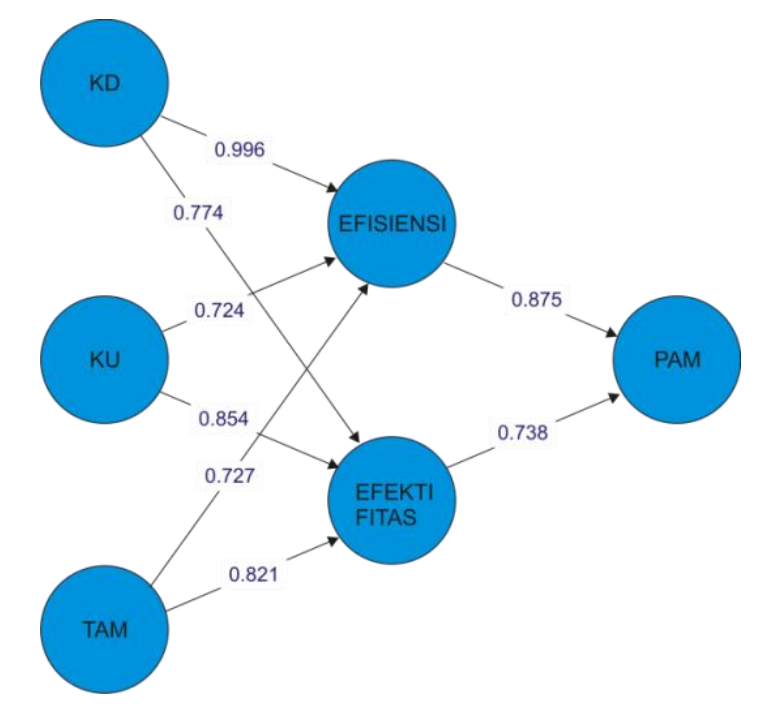

Figure 2.Construction Model Test Results

Source: processed smartPLS output (2019)

It's obtained the value of the coefficient of the line between the construction above 0.7 from the test results of the coefficient of the existing construction path in figure 2 This means that all constructs submitted are positively interconnected, which allows for the acceptance of all hypotheses.

Table 5. Hypothetical Test Results

\begin{tabular}{lccc} 
Path Construct & $\begin{array}{c}\text { Original sample } \\
\text { estimate }\end{array}$ & $\begin{array}{c}\text { Standard } \\
\text { deviation }\end{array}$ & T-Statistic \\
\hline KD -> EFIS & 0.996 & 0.031 & 19.281 \\
KD -> EFEK & 0.774 & 0.044 & 23.209 \\
KU -> EFIS & 0.724 & 0.039 & 11.008 \\
KU -> EFEK & 0.854 & 0.026 & 31.297 \\
TAM -> EFIS & 0.727 & 0.041 & 27.287 \\
TAM -> EFEK & 0.821 & 0.047 & 43.115 \\
EFIS -> PAM & 0.875 & 0.023 & 56.942 \\
EFEK -> PAM & 0.738 & 0.038 & 38.627 \\
\hline SOurce: ProCessed
\end{tabular}

Source: processed smartPLS output (2019)

Hypothesis 1 discusses the positive relationship between efficiency and PAM. Based on the discussion, the accepted hypothesis should show a significant and positive relationship at $\mathrm{p}=$ 0.05 with a statistical $t$ value above 1.96 (56.94), so that the increase in efficiency will encourage changes in AM practice. Then Hypothesis 2 discusses and confirms the positive relationship between effectiveness and PAM ( $p=0.05$, statistical t 38.62). Meanwhile, positive relationships between data quality (KD) and efficiency and effectiveness were discussed in Hypothesis $3 \mathrm{a}$ and $3 \mathrm{~b}$ respectively. This hypothesis is accepted by indicating a significant and positive relationship at $\mathrm{p}=0.05$ with a statistical t-value above 1.96 (19.28 and 23.20), respectively). Hypotheses 4a 
and $4 \mathrm{~b}$ suggest that improving the quality of information (KU) will positively affect efficiency and effectiveness. This hypothesis was accepted supported by a positive and significant relationship at $\mathrm{p}=0.05$ with a statistical t-value above 1.96 (11.00 and 31.29), respectively). Hypotheses $5 \mathrm{a}$ and $5 \mathrm{~b}$ indicate a change in the task of management accountants (TAM) related with effectiveness and efficiency. The positive relationship is shown a path of coefficient with tstatistical values of 27.28 and 43.11 at $\mathrm{p}=005$ significance, respectively. Therefore, the use of business intelligence tools in the form quality of data, information quality and management accountant duties have a positive effect on efficiency, effectiveness and application of new techniques of accounting management, thus the proposed model has relevant predictions.

The contributions that will be submitted based on this research, namely, the existence of accounting literature from various ways. Generated support for the statement that improving the quality of information (KU) improves the efficiency and effectiveness of accounting. Furthermore, data quality is seen as a driver of increased effectiveness and has a significant influence on efficiency. In addition, from these results, it was concluded that changes in duties from management accountants indirectly influenced the change in AM practice. Other results showed a significant positive relationship of changes in AM practice and efficiency. In short, this study contributed to empirical testing and verifying the relationship between various factors related to data/information quality and accountant's duties on efficiency and effectiveness and indirectly on changes in AM practice. This study responds to suggestions from previous research that tests si success models in various contexts (Rai et al., 2006; Petter et al., 2008, Gulkvist, 2013).

In addition, AM type changes are statistically influenced by the success of significant ERP implementations. Later, Sangster et al. (2009) argued that "identifying improved data quality, better decision making and changes in accountant tasks under successful ERP implementation, this study adds to these findings by emphasizing changes in AM techniques related to successful ERP implementation."

Relevant to the reasons for previous (Granlund and Malmi, 2002), "the results of this study show that the time since ERP adoption is a significant determinant of changes in AM techniques, but also that most changes occur within eight years after ERP implementation." In addition, more late ERP adopters feel changes in AM techniques than early adopters. Then, based on this research found that significant determinants of changes in AM techniques include the scope of installations either locally or globally. In previous research, they have not found it, so it can be concluded that this research offers something new in ERP implementation, which is related to time.

then, the conference from this study Wieder et al (2012) "findings regarding the significant relationship between IB tools and data quality, it also suggests that the effects of IB tools may be difficult to quantify as they may be related to a variety of problems. There may be several explanations for that, one of which is that the level of integration between IB tools and ERP systems may differ and affect how IB tools are associated with changes in AM practice." It seems, however, in order to facilitate changes in AM practice and to add value additional tools are needed in the ERP system. More than that, due to limited research on changes in AM practice, practitioners, companies and research communities need to know what is improving the understanding of what drives AM change in ERP environment. Someone who is in the accounting profession needs to improve the understanding of the effect of ERP systems on AM practices. In practice, the factors that influence to change AM practice, such as AM planning, development, and practice management in the event of a change, need to be considered. 


\section{CONCLUSION}

Results of this study showed consistency with previous research, where the determinant of a significant AM change is the time of ERP implementation, but the end user, namely the company that has implemented the ERP system, found that they felt a greater AM change than the user first. In addition, a significant change in AM practice in this study, was influenced by the use of business intelligence tools (IB) and the implementation of ERP as a whole. However, there are some limitations of this research. First, the causal relationship is difficult to conclude, it's caused, the data is only obtained at one point in time. Second, the method of survey questionnaires often has limitation, it because the questionnaire is not considered to show the actual practice. Another limitation is the use of scale in measuring core construction, where the operationalization of variables and problems is measured by self-assessment. In addition, although a single scale can show validation, but a multi-type scale is more able to show good results overall. Using one indicator is one of the drawbacks of this study. Third, in empirical studies generalization is its main concern, so in the absence of replication, the success of generalization cannot be determined what is the effect of sample size. In addition, small sample sizes and low response rates also indicate the need for caution in drawing conclusions based on findings.

So, it is recommended for further research can do research on other factors that can increase changes in AM practice. The use of IB tools significantly turned out to cause good changes in AM practice, this is very interesting, so it is expected that the next researchers can continue this. In addition, external environmental factors in each company vary also need to be considered, but specifically in this study, we did not take into account it. so that this can be considered for further researchers or academics and practitioners, because considering the importance of finding items that can improve AM practice in an ERP environment.

\section{REFERENCE}

Arnold, V. and Sutton, S.G. (1998), The theory of technology dominance: Understanding the impact of intelligent decision aids on decision-makers' judgments. Advances inAccounting Behavioral Research, 1, pp. 175-194.

Barclay, D., Higgins, C. and Thompson, R., (1995), The Partial Least Squares (PLS) approach to causal modeling: Personal computer adoption and use as an illustration. Technology Studies, 2, 2, pp. 285-324.

Bernroider, E.W.N. (2008). IT governance for enterprise resource planning supported by the DeLone-McLean model of information systems success. Information \& Management, 48, 5, pp. 257-269.

Booth, P., Matolcsy, Z. and Wieder, B. (2000).The Impacts of Enterprise Resource Planning Systems on Accounting Practice: The Australian Experience.Australian AccountingReview, 10, 22, pp. 4-18.

Bradley, R.V., Pridmore, J.L. and Byrd, T.A. (2006).Information systems success in the context of different corporate cultural types: An empirical investigation. Journal ofManagement Information Systems, 23, pp. 267-294.

Chin, W. (1998), The partial least squares approach to structural equation modeling. Modern Methods for Business Research, Lawrence Erlbaum, Mahwah, NJ, pp. 295-336. 
Cooper, R. and Kaplan, R. S. (1998).The promise - and peril - of integrated cost systems.Harvard Business Review, July-August, pp. 109-119.

Dechow, N. and Mouritsen, J. (2005).Enterprise resource planning systems, management control and the quest for integration. Accounting, Organizations and Society, 30, 7-8,pp. 691-733.

DeLone, W. H. and McLean, E. R. (1992). Information systems success: The quest for the dependent variable. Information Systems Research, 3, 1, pp. 60-95.

DeLone, W.H. and McLean, E.R. (2003).The DeLone and McLean Model of Information Systems Success: A ten-year update.Journal of Management Information Systems, 19, 4, pp. 9-30.

Dillman, D. A. (2000)Mail and Internet Surveys: The Tailored Design Method, John Wiley, New York.

Drury, C. and Tayles, M. (1995).Issues arising from surveys of management accounting practice.Management Accounting Research, 6, pp. 267-280.

Ghozali, Imam. (2011). Structural Equation Modeling, Metode Alternatif dengan Partial Least Square (edisi ketiga). Badan Penerbit: Universitas Diponegoro, Semarang.

Gorla, N. Somers, T.M. and Wong, B. (2010).Organizational impact of system quality, information quality, and service quality.Journal of Strategic Information Systems, 19, pp. 207-228.

Grabski, S. and Leech, S. (2007). Complementary controls and ERP implementation success.International Journal of Accounting Information Systems, 8, 1, pp. 17-39.

Granlund, M. (2011).Extending AIS research to management accounting and control issues: A research note. International Journal of Accounting Information Systems, 12, 1, pp. 3-19.

Granlund, M. and Malmi, T. (2002).Moderate impact of ERPS on management accounting: A lag or permanent outcome. Management Accounting Research, 13, 3, pp. 299-321.

Gulkvist, B.M. (2013).Drivers of change in management accounting practices in an ERP environment. International Journal of Economic Sciences and Applied Research, 6, 2, pp. 149-174.

Hevner, A. R., March, S. T. Park, J. and Ram, S. (2004).Design science in information systems research. MIS Quarterly, 28, 1, pp. 75-105.

Hunton, J. E. (2002).Blending information and communication technology with accounting research. Accounting Horizons, 16, 1, pp. 55-67.

Kallunki, J-P., Laitinen, E.K. and Silvola, H. (2011).Impact of Enterprise Resource Planning Systems on MACS and Performance of the Firm.International Journal ofAccounting Information Systems, 12, pp. 20-39.

Kock, Ned. (2015). Common method bias in PLS-SEM: A full collinearity assessment approach. International Journal of e-Collaboration, 11,4, pp. 1-10.

Kondalkar, V.G. (2009).Organization Effectiveness and Change Management, PHI Learning Private Limited, New Delhi.

Laitinen, E.K. (2002).A dynamic performance measurement system: Evidence from small Finnish technology companies. Scandinavian Journal of Management, 18, 1, pp. 65-99.

Melville, N., Kraemer, K. and Gurbaxani, V. (2004). Review: Information technology and organizational performance: An integrated model of business value.MIS Quarterly, 28, 2, pp. 283-322.

Nicolaou, A.I. (2000).A contingency model of perceived effectiveness in accounting information systems: Organizational coordination and control. International Journalof Accounting Information Systems, 1, 2, pp. 91-105. 
Nicolaou, A.I. (2003).Manufacturing strategy implementation and cost management systems effectiveness.European Accounting Review, 12, 1, pp. 175-199.

Nicolaou, A.I. and Bhattacharya, S. (2006).Organizational performance effects of ERP systems usage: the impact of post-implementation changes. International Journal ofAccounting Information Systems, 7, 1, pp. 18-35.

Park, K. and Kusiak, A. (2005).Enterprise resource planning (ERP) operations support system for maintaining process integration. International Journal of ProductionResearch, 43, 19, pp. 3959-3982.

Petter, S., DeLone, W. and McLean, E. (2008).Measuring information systems success: Models, dimensions, measures, and interrelationships.European Journal of InformationSystems, 17, pp. 236-263.

Rai, A., Patnayakuni, R. and Seth, N. (2006).Firm performance impacts of digitally enabled supply chain integration capabilities. MIS Quarterly, 30, pp. 225-246.

Redman, T.C. (1998).The impact of poor data quality on the typical enterprise. Communications of the ACM, 41, pp. 79-82.

Ringle, C. M ., Wende, S. and Will, S. (2005)SmartPLS 2.0 (M3), Hamburg.

Rom, A and Rohde, C. (2006).Enterprise resource planning systems, strategic enterprise management systems and management accounting. A Danish study. Journal ofEnterprise Information Management, 19, 1, pp. 50-66.

Sangster, A., Leech, S.A. and Grabski, S. (2009).ERP implementations and their impact upon management accountants. Journal of Information Systems and TechnologyManagement, 6, 2, pp.125-142.

Scapens, R.W. and Jazayeri, M. (2003).ERP systems and management accounting change: opportunities or impacts? A research note. European Accounting Review, 12, 1, pp.201233.

Smithson, S. and Hirschheim, R. (1998). Analyzing Information System Evaluation: Another Look at an Old Problem.European Journal of Information Systems, 7, pp. 158-174.

Spathis, C. (2006).Enterprise systems implementation and accounting benefits. Journal of Enterprise Information Management, 19, 1, pp. 67-82.

Sutton, S.G. (2006).Enterprise systems and the re-shaping of accounting systems: A call for research. International Journal of Accounting Information Systems, 7, 1, pp. 1-6.

Swanson, B. (1997). Maintaining IS quality.Information and Software Technology, 39, pp. 845850.

Tsai, W-H., Shaw, M.J., Fan, Y-W., Liu, J-Y., Lee, K-C., Chen, H-C. (2011). An empirical investigation of the impacts of internal/external facilitators on the project success of ERP: A structural equation model. Decision Support Systems, 50, 2, pp. 480-490.

Vakalfotis, N., Ballantine, J. and Wall, A. (2011).A literature review on the impact of Enterprise Systems on management accounting. Proceedings of the 8th InternationalConference on Enterprise Systems, Accounting and Logistics, Thassos Island, Greece, pp. 79-105. 